\title{
DESIGN AND DEVELOPMENT OF ITERATIVE SQUARE RING FRACTAL ANTENNA FOR DUAL BAND APPLICATIONS
}

\author{
Gulfa Rani ${ }^{1}$ and Robinson $\mathrm{S}^{2}$ \\ Department of Electronics and Communication Engineering, \\ Mount Zion College of Engineering and technology, Pudukkottai, India - 622507
}

\begin{abstract}
In this paper, iterative square ring fractal antenna is proposed, designed and developed for Wireless application. The functional characteristics of the antenna such as return loss, VSWR, radiation pattern and gain are evaluated. Compact size and multi-band compatibility are the major design requirements of fractal antenna. The proposed antenna has the dimension of $20 \mathrm{~mm} \mathrm{X} \mathrm{20mm} \mathrm{and} \mathrm{it} \mathrm{supports} \mathrm{dual} \mathrm{band}$ which is designed in FR4 substrate. It resonates at $5.9 \mathrm{GHz}$ and $8.8 \mathrm{GHz}$ with the return loss of -33dB, $16 \mathrm{~dB}$, respectively. Further, the performance of the antenna is analyzed by varying feed position, feed width and substrate thickness. By the analysis, we concluded that the proposed antenna have better performance at left feed position with $0.9 \mathrm{~mm}$ of feed width at the substrate thickness of $3.2 \mathrm{~mm}$.
\end{abstract}

\section{KEYWORDS}

WLAN, Fractal, Square Ring, X Band, FR4, Antenna.

\section{INTRODUCTION}

Rapid growth in wireless communication demands extremely compact antenna with wider bandwidth [1], high data rate, low power requirements and easy hardware configuration [2]. The swift deployment of short distance wireless communications such as Wireless Local Area Networks (WLANs) is demanding for compact, low cost, multiband and broadband antenna [3]. There are several types of antenna like microstrip patch antenna, reflector antenna, aperture antenna, travelling wave antenna, vertical antenna that support wireless applications with acceptable loss $[4,5]$. However, the miniaturization and multiband support of fractal antenna makes it more appropriate for implementation.

Typically, the fractal concept was originally developed by Benoit Mandelbrot. The word fractal was derived from a Latin word "Fractus" [6]. The key aspect of fractal is the repetition of a motif over two or more scale sizes or iterations. [7]. There are many naturally available fractal structures like plants, leaves, alp ranges etc [8]. There are two prime properties for fractal such as Space filling and Self similarity. A space-filling tree is defined by an iterative process whereby a single point in a continuous space is connected via a continuous path to every other point in the space by a path of finite length, and for every point in the space, there is at least one path that converges to it. Self-similarity is a typical property of fractals. Scale invariance is an exact form of self-similarity where at any magnification there is a smaller piece of the object that is similar to the whole [9].

The multiband and ultra wide band properties are supported by fractal antenna because of its self similarity property [10]. Then the implementation of complex space filling fractal geometry 
resonates at comparably lower frequencies than any other antennas of similar size [11]. These two properties made the fractal antenna more compact and suitable for wideband and multi- band behavior. The self similarity property of the fractal enhances the performance of the antenna only up to a certain extent.

Many researchers have attempted fractal antenna with different shapes like inner tapered treeshape [12], poly fractal boundary [13], Octagonal fractal [14], SRR-Based Polygon Ring [15], simple multiband patch antenna [16], and Circularly Polarized Asymmetrical Fractal [17]. Considering the hardware complexity incase of compactness and denial of multiband behavior [18] in other antennas, the proposed fractal antenna is miniaturized and supports dual band applications.

In this paper, iterative square ring shaped fractal antenna is proposed, designed and developed for WLAN and $\mathrm{X}$ band applications that are centered at $5.9 \mathrm{GHz}$ and $8.8 \mathrm{GHz}$, respectively. The functional parameters of the proposed antenna such as resonant frequency, return loss, radiation pattern, VSWR are analyzed through simulation. Then the proposed antenna is developed and its measured results are compared with simulated one. Further, the variation in return loss while varying the substrate thickness, feed position and feed width are investigated through simulation. The remaining part of the paper is organized as follows; the design of the iterative square ring shaped antenna is presented in Section II. In Section III the simulated and measured results are discussed. The impact of return loss while varying the frequency for different substrate thickness, feed width and feed position are described in Section IV. Finally Section V concludes the paper.

\section{AnTEnNa Design}

Fig. 1 shows the proposed fractal antenna. It is composed of microstrip fed monopole printed on a FR4 epoxy substrate with compact size of $20 \mathrm{~mm} \mathrm{X} 20 \mathrm{~mm}$, thickness of $3.2 \mathrm{~mm}$, relative permittivity of $\xi_{r}=4.4$ and loss tangent of 0.02 is proposed.

The proposed antenna basically have rectangular copper patch with two different sizes of square ring shaped slots. The slot sizes are not decreased further due to fabrication limitations. FR4 substrate is chosen for the design as it is easily available and has good fabrication characteristics comparing with other substrate materials. Microstrip feeding technique with the characteristic impedance of $50 \Omega$ is used in the proposed antenna. The dimension details of the proposed antenna are listed in Table 1.

Table 1: Details of the Proposed Antenna with its value

\begin{tabular}{|l|l|}
\hline Particulars & Size (mm) \\
\hline Dimension of substrate & 20 X 20 \\
Thickness of substrate & 3.2 \\
Outer ring dimension & $15 \times 15$ \\
Inner ring dimension & 4 X 4 \\
Side outer ring dimensions & $4.5 \times 4.5$ \\
Side inner ring dimensions & $1.5 \times 1.5$ \\
Width of the feed & 0.9 \\
\hline
\end{tabular}




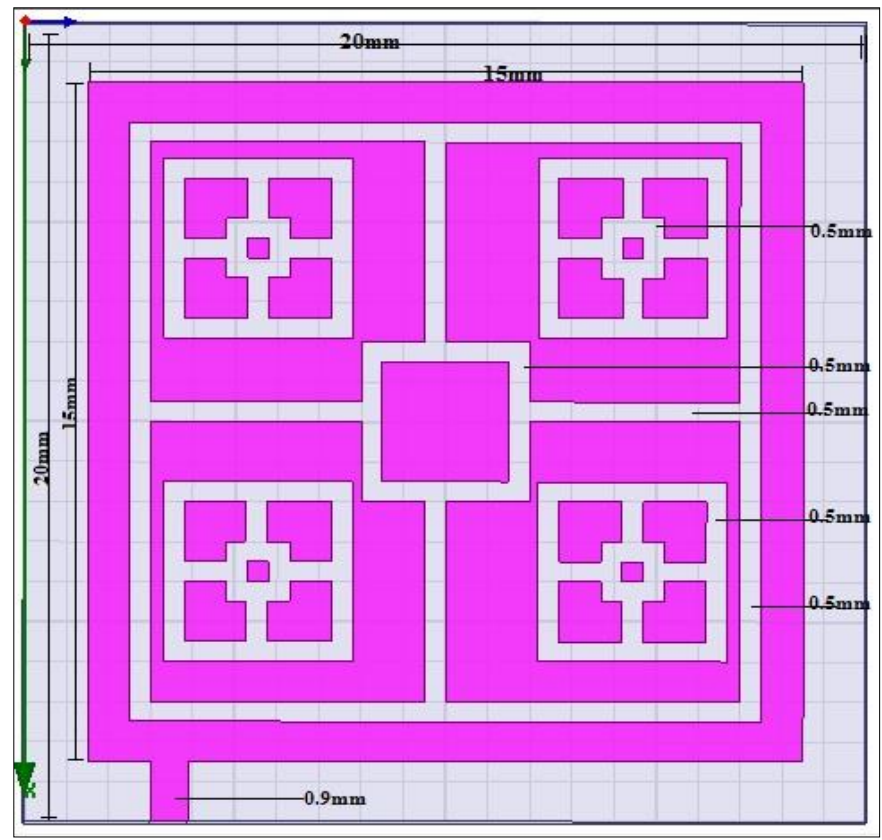

Fig. 1 Proposed iterative square ring fractal antenna

The fabricated prototype of the proposed antenna compared with the size of the coin is shown in Fig. 2. From the Fig. 2, it is seen that the size of the developed antenna is very small than the reported one. However, the performance of the antenna is better which is discussed in the next session.

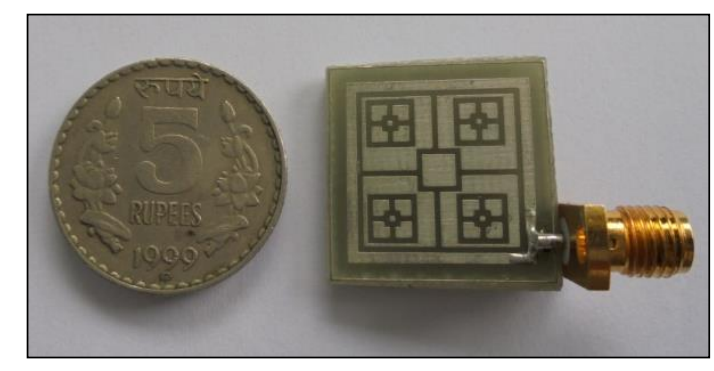

Fig. 2 Fabricated prototype of the proposed antenna

\section{RESULT AND DISCUSSION}

All the simulated data of the proposed antenna have been obtained by means of an electromagnetic simulator on the Finite Element Method [FEM] [19]. Parameters such as S parameters, resonant frequency and fields can be simulated using the simulator. Frequency domain analysis is selected while simulating the model. Return loss is one of the vital parameter that defines the performance of the antenna. The return loss is the measure of how much power is reflected back to the antenna due to mismatch. From the Fig. 3, it is noticed that the return loss and resonant frequency of the proposed antenna is about $-33.0636 \mathrm{~dB},-16.3700 \mathrm{~dB}$ at $5.9 \mathrm{GHz}$, $8.8 \mathrm{GHz}$, respectively. The $10 \mathrm{~dB}$ bandwidth of the proposed antenna at $5.9 \mathrm{GHz}$ and $8.8 \mathrm{GHz}$ is $542 \mathrm{MHz}$ and $540 \mathrm{MHz}$ respectively. The return loss of the antenna can be theoretically calculated by, 


$$
\text { Return Loss }(\mathrm{dB})=20 \log (\gamma)----
$$

$$
\gamma=\text { Reflection Coefficient }
$$

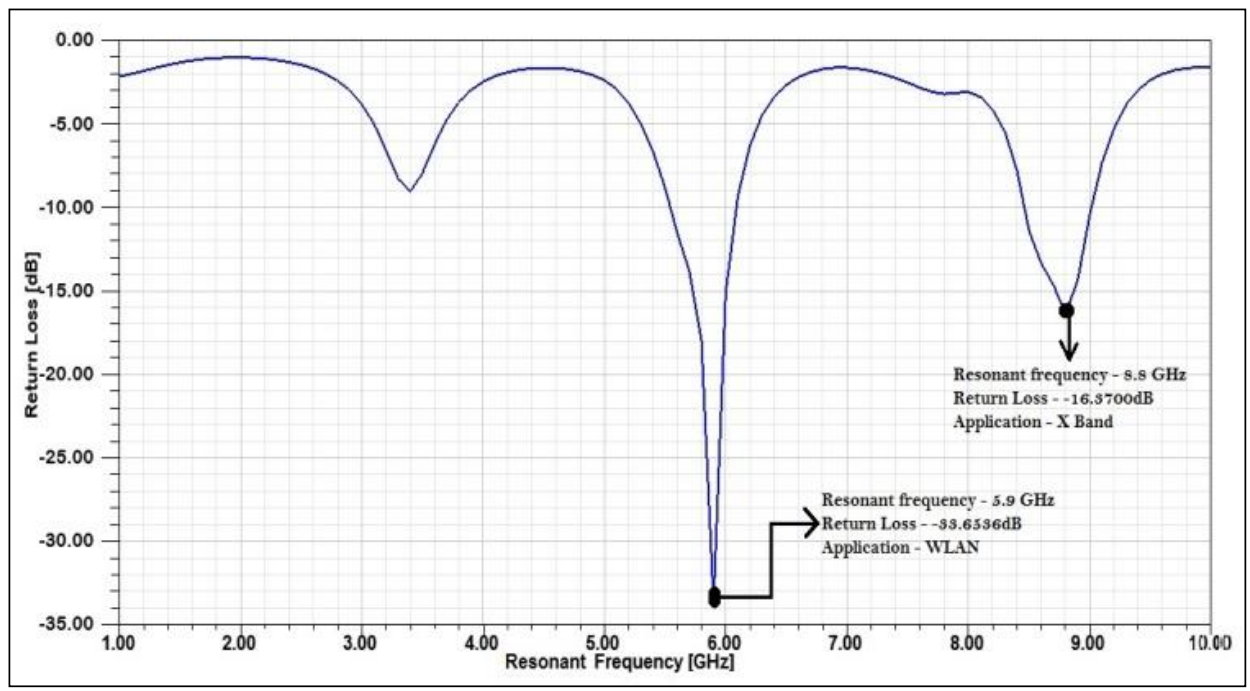

Fig. 3 Simulated return loss response of the proposed antenna

The comparison of simulated and measured return loss is shown in Fig. 3. From this result it is noticed that there is a trivial change in the measured return loss. This discrepancy between measured and simulated one might be due to effect of soldering the sub miniature version (SMA) connector or fabrication tolerance and material tolerance of the substrate.

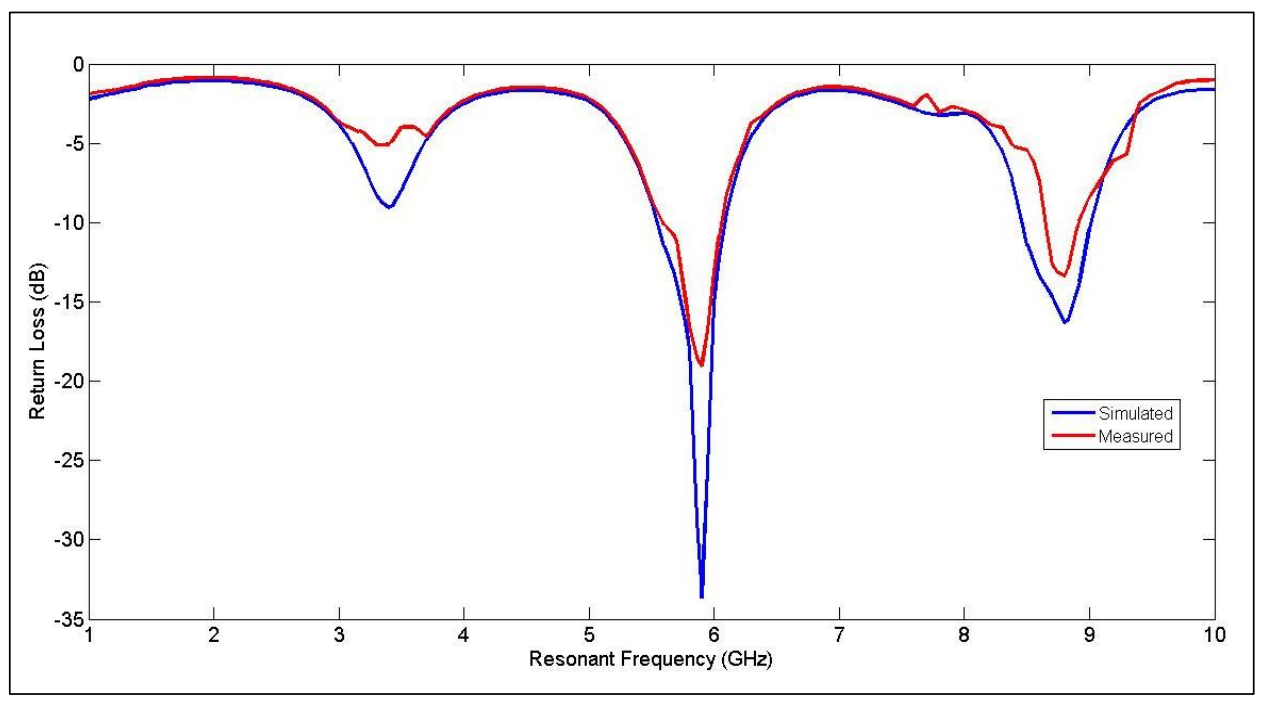

Fig.4 Comparison graph of simulated and measured return loss of the proposed antenna

The impact of VSWR with respect to the frequency is shown in Fig. 5. The attained value of VSWR is $1.0424,1.3582$ at $5.9 \mathrm{GHz}, 8.8 \mathrm{GHz}$, respectively. Generally, VSWR is obtained by,

$$
V S W R=\frac{1+\gamma}{1-\gamma}
$$




\section{$\gamma=$ Reflection Coefficient}

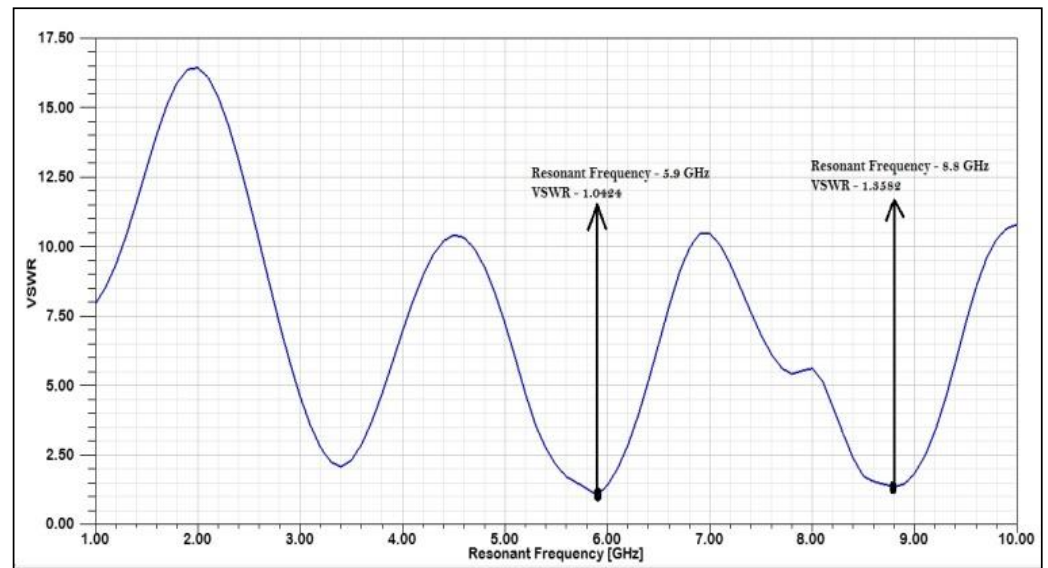

Fig. 5 Simulated VSWR response of proposed antenna

A radiation pattern defines the variation of the power radiated by an antenna as a function of the direction away from the antenna. The far field radiation pattern of the proposed antenna at $5.9 \mathrm{GHz}, 90^{\circ}$ and $8.8 \mathrm{GHz}, 90^{\circ}$ are shown in Figs. 6 (a) and 6 (b), respectively. The radiation pattern clearly proves that the proposed antenna is directional.

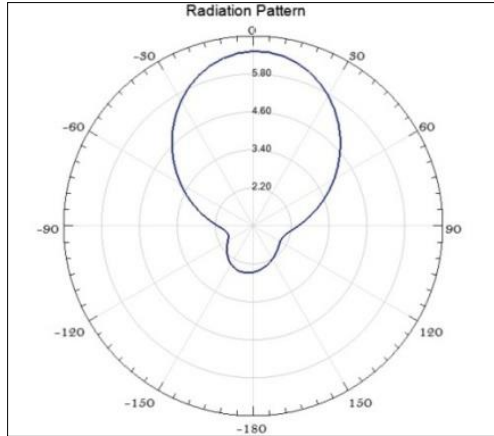

(a)

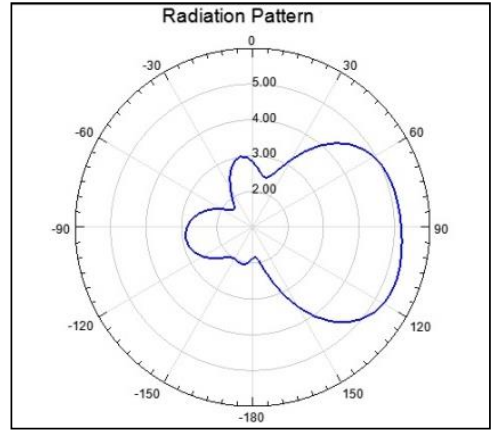

(b)

Fig. 6 Radiation pattern of the proposed antenna at (a) $5.9 \mathrm{GHz}$ and (b) $8.8 \mathrm{GHz}$

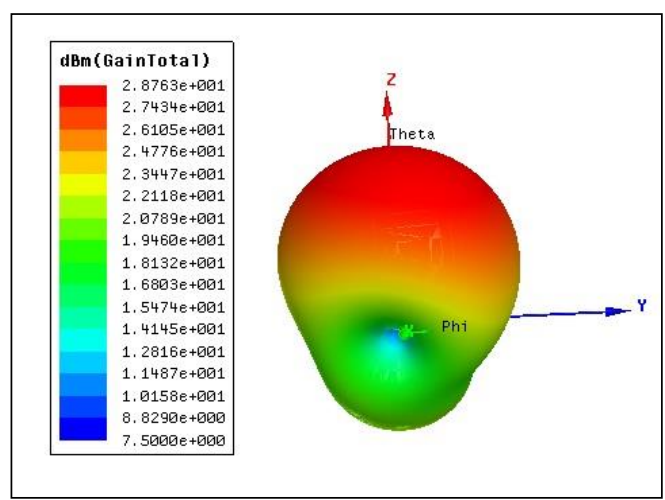

(a)

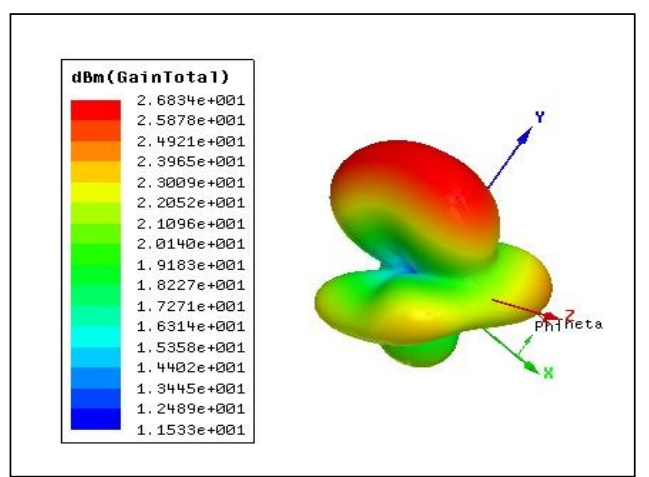

(b)

Fig. 7 The simulated 3D-total gain pattern of the proposed antenna at (a) $5.9 \mathrm{GHz}$ and (b) $8.8 \mathrm{GHz}$ 
Apart from the analysis of return loss and VSWR, the performance of the antenna is also analyzed in terms of antenna gain and current distribution as depicted in Fig. 7 and Fig. 8, respectively. The gain of the proposed antenna is $2.87 \mathrm{~dB}$ at $5.9 \mathrm{GHz}$ and $2.6 \mathrm{~dB}$ at $8.8 \mathrm{GHz}$ which is shown in Figs 7(a) and 7(b), respectively. Usually the gain the antenna should be positive and it could be upto $70 \mathrm{~dB}$. In Fig. 8 the red color shows the maximum current distribution and the blue color indicates the minimum color distribution. It clearly states that the current distribution is good near the slots.

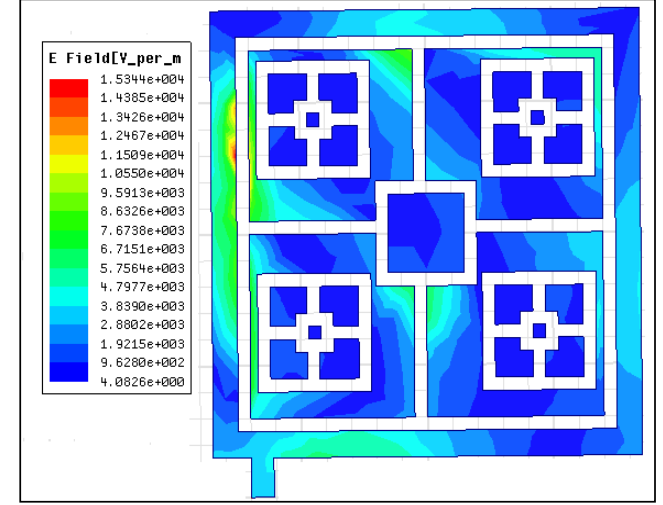

(a)

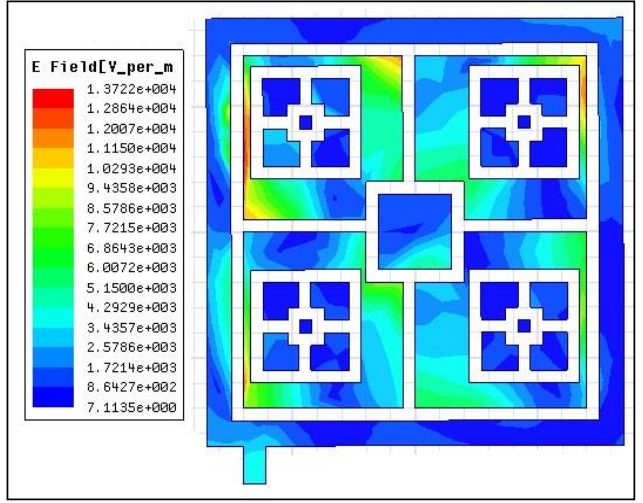

(b)

Fig. 8 The simulated current distribution pattern of the proposed antenna (a) $5.9 \mathrm{GHz}$ and $\quad$ (b) $8.8 \mathrm{GHz}$ The obtained functional parameters of the proposed antenna such as return loss, VSWR, resonant frequency, radiation pattern and $10 \mathrm{~dB}$ bandwidth are meeting the requirements for WLAN and X band applications. Hence it could be realized for real time applications.

\section{Parametric Analysis}

In this section, the impact of return loss while varying the frequency for different substrate thickness, feed position and feed width are presented. In FR4, three different substrate thicknesses are currently available i.e., $0.8 \mathrm{~mm}, 1.6 \mathrm{~mm}$ and $3.2 \mathrm{~mm}$. The substrate thickness is selected based on the desired applications. The substrate thickness of $3.2 \mathrm{~mm}$ is chosen because the proposed antenna performs well at the considered application frequency rather than other substrate thicknesses. The impact of return loss at different substrate thickness is shown in Fig. 9, which clearly denoted that at the substrate thickness of $3.2 \mathrm{~mm}$ antenna performs better than other sizes. The return loss, resonant frequency for different substrate thickness is tabulated in Table. 2

Table 2 Resonant Frequency, Return Loss for different Substrate Thickness.

\begin{tabular}{|l|l|l|}
\hline $\begin{array}{l}\text { Substrate } \\
\text { Thickness }(\mathbf{m m})\end{array}$ & $\begin{array}{l}\text { Resonant } \\
\text { Frequency }(\mathbf{G H z})\end{array}$ & $\begin{array}{l}\text { Return Loss } \\
(\mathbf{d B})\end{array}$ \\
\hline \multirow{2}{*}{0.8} & 5.9 & -4.06203 \\
& 8.8 & -4.29039 \\
\hline \multirow{2}{*}{1.6} & 5.9 & -7.37194 \\
& 8.8 & -6.45922 \\
\hline \multirow{2}{*}{3.2} & 5.9 & -33.6536 \\
& 8.8 & -16.3700 \\
\hline
\end{tabular}




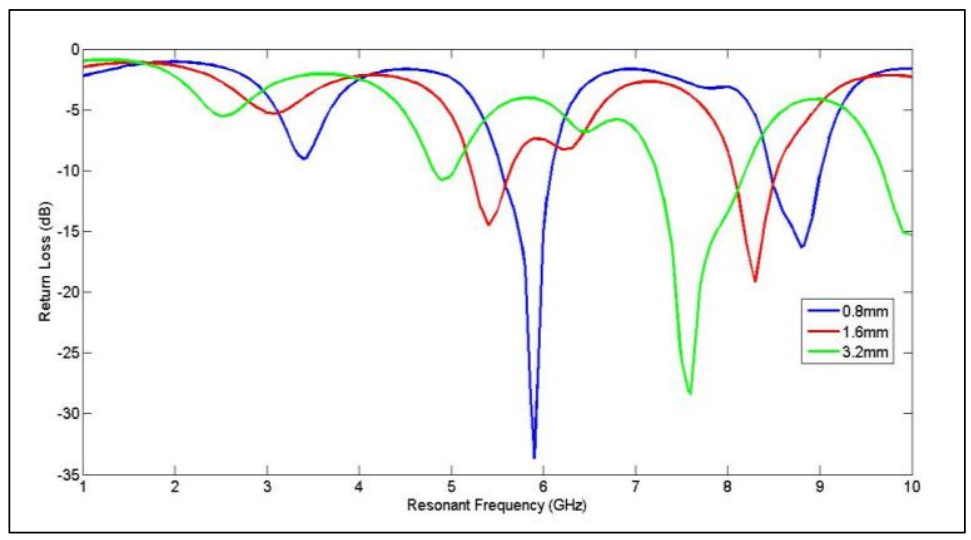

Fig. 9 Return loss Vs Resonant frequency for different values of Substrate Thickness

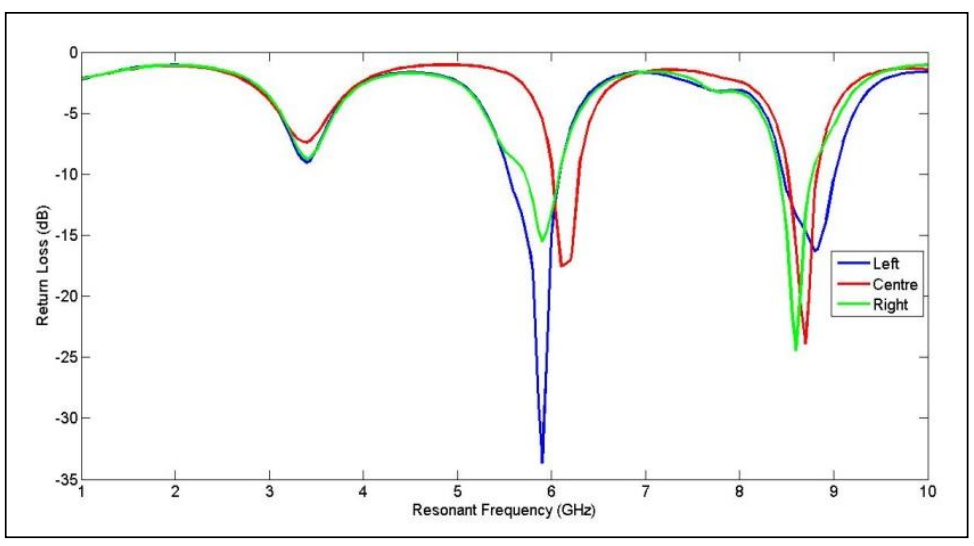

Fig. 10 Return loss Vs Resonant frequency for different values of Feed Position

Fig. 10 shows the change in return loss by varying the feed position. It is noticed that, the return loss is high at right and centre feed position. However, the return loss is reached about $-33 \mathrm{~dB}$ when the feed is placed at left position. Hence, the feed is considered from the left side. The functional parameters of a proposed antenna at different feed position are listed in Table 3.

Table 3 Resonant Frequency, Return Loss for different Feed Position.

\begin{tabular}{|l|l|l|}
\hline Feed Position & $\begin{array}{l}\text { Resonant } \\
\text { Frequency }(\mathbf{G H z})\end{array}$ & $\begin{array}{l}\text { Return } \\
\text { Loss }(\mathbf{d B})\end{array}$ \\
\hline \multirow{2}{*}{ Left } & 5.9 & -33.6536 \\
& 8.8 & -16.3700 \\
\hline \multirow{2}{*}{ Centre } & 5.9 & -5.5675 \\
& 8.8 & -11.3475 \\
\hline \multirow{2}{*}{ Right } & 5.9 & -15.5419 \\
& 8.8 & -9.2094 \\
\hline
\end{tabular}

Finally, in order to optimize the width of the feed, the simulation is carried out by having different size of feed width. In this case, the feed position and substrate thickness is considered as left feed position and $3.2 \mathrm{~mm}$, respectively. The variation in return loss while varying the feed width is reported in Fig. 11. The return loss, VSWR, resonant frequency for different feed width is tabulated in Table. 4 


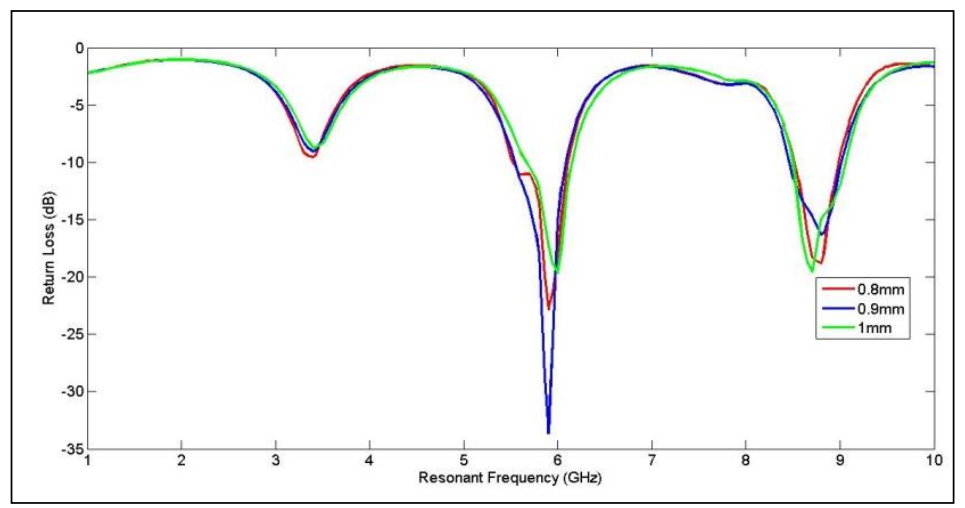

Fig. 11 Return loss Vs Resonant frequency for different values of Feed Width

Table 4 Resonant Frequency, Return Loss for different Feed Width.

\begin{tabular}{|l|l|l|}
\hline $\begin{array}{l}\text { Feed } \\
\text { Width }(\mathbf{m m})\end{array}$ & $\begin{array}{l}\text { Resonant } \\
\text { Frequency }(\mathbf{G H z})\end{array}$ & $\begin{array}{l}\text { Return Loss } \\
(\mathbf{d B})\end{array}$ \\
\hline \multirow{2}{*}{0.8} & 5.9 & -22.8385 \\
& 8.8 & -18.8328 \\
\hline \multirow{2}{*}{0.9} & 5.9 & -33.6536 \\
& 8.8 & -16.3700 \\
\hline \multirow{2}{*}{1} & 5.9 & -17.3432 \\
& 8.8 & -14.9625 \\
\hline
\end{tabular}

From the aforementioned simulations, it is investigated that the proposed iterative square ring fractal antenna has performed better at the substrate thickness of $3.2 \mathrm{~mm}$, left feed position and feed width of $0.9 \mathrm{~mm}$. Hence, the above reported values are employed in the proposed antenna.

\section{Conclusion}

In this paper, a fractal antenna is proposed, designed and developed for WLAN and X band applications. The performance parameters of the antenna namely, resonant frequency, VSWR, return loss and $10 \mathrm{~dB}$ bandwidth is analyzed. From the simulation, $-33.0636 \mathrm{~dB},-16.3700 \mathrm{~dB}$ of return loss and 1.0424, 1.3582 of VSWR is obtained at $5.9 \mathrm{GHz}, 8.8 \mathrm{GHz}$. The size of the antenna is compact about $20 \mathrm{~mm} \times 20 \mathrm{~mm}$. Further, the feed position, feed width and substrate thickness is optimized through simulation. The present work is fulfilling the primary requirements of WLAN as well as X band applications; therefore, the proposed antenna can be incorporated for real time application of wireless devices.

\section{REFERENCES}

[1] Simarpreet Kaur, Rajni and Gurwinder Singh, "On the Bandwidth Enhancement of Modified StarTriangular Fractal Antenna”, Proceedings of the International Conference on Recent Cognizance in Wireless Communication \& Image Processing, Springer India, pp. 703-710, 2016.

[2] Jalali M and Sedghi T, "Very compact UWB CPW-fed fractal antenna using modified ground plane and unit cells", Microwave Opt Technol Lett 56 pp. 851-854, 2014.

[3] D. Li, F.-S. Zhang, Z.-N. Zhao et al., "A CPW-Fed wideband koch snowflake fractal monopole for WLAN/WiMAX applications”, Progress In Electromagnetics Research C, Vol. 28, pp. 143- 153, 2012.

[4] Graf, Rudolf F. (1999). Modern Dictionary of Electronics. Newnes. p. 29.ISBN 0750698667.

[5] Chaimool S, Chokchai C, and Akkaraekthalin P, "Multiband loaded fractal loop monopole antenna for USB dongle applications", Electronics Letters Vol. 48, pp. 1446-1447, 2012. 
[6] C. Mahatthanajatuphat, S. Saleekaw, and P. Akkaraekthalin, "A rhombic patch monopole antenna with modified minkowski fractal geometry for UMTS, WLAN, and mobile WIMAX application", Progress in Electromagnetics Research, PIER 89, pp. 57-74, 2009.

[7] R. K. Yadav, J. Kishor and R. L. Yadava, "A Chaucer Microstrip Fractal Antenna for Mobile Applications",Journal of Communications Technology and Electronics, 2016, Vol. 61, No. 2, pp. 138-144, 2016.

[8] Rohit Gurjar, Ravi Singh and Saurabh Kumar, "Elliptically Slotted Self-affine 8-Shaped Fractal Multiband Antenna" , Proceedings of the International Conference on Recent Cognizance in Wireless Communication \& Image Processing, Springer India, pp. 783-789, 2016.

[9] Mandelbrot, Benoit B. (1982). The Fractal Geometry of Nature, p.44.

[10] Raj Kumar and P. Malathi, "Design of CPW -Fed Ultra wideband Fractal Antenna and Backscattering Reduction", Journal of Microwaves, Optoelectronics and Electromagnetic Applications, Vol. 9, No. 1, pp 10-19, 2010.

[11] C. Puente-Baliarda, J. Romeu, and A. Cardama, "The Koch monopole: A small fractal antenna," IEEE Trans. Antennas Propagat., Vol. 48, pp.1773-1781, 2000.

[12] Sarthak Singhal, Tushar Goel, and Amit Kumar Singh, "Inner Tapered Tree-Shaped Fractal Antenna for UWB Applications", Microwave and Optical Technology Letters, Vol. 57, No. 3, pp. 559-567, 2015.

[13] Reddy V. V, Sarma N V.S.N, "Poly Fractal Boundary Circularly Polarized Microstrip Antenna for WLAN/Wi-MAX Wireless Applications”, Defence Science Journal, Vol. 65, No. 5, pp. 379-384, 2015.

[14] Shrivishal Tripathi, Akhilesh Mohan and Sandeep Yadav, "A compact octagonal fractal UWB MIMO antenna with WLAN band- rejection", Microwave And Optical Technology Letters, Vol. 57, No. 8, pp. 1919-1925, 2015.

[15] Rajeshkumar V and Singaravelu Raghavan, "SRR-based polygon ring Penta-band fractal antenna for GSM/WLAN/WIMAX/ITU band applications", Microwave And Optical Technology Letters, Vol. 57, No. 6, pp. 1301-1305, 2015.

[16] Bayatmaku N, Lotfi P, Azarmanesh M, and Soltani S, "Design of simple multiband patch antenna for mobile communication applications using new E-shape fractal", IEEE Antennas Wireless Propag Lett 10, pp. 873-875, 2011.

[17] Reddy V. V and Sarma N. V. S. N, "Compact Circularly Polarized Asymmetrical Fractal Boundary Microstrip Antenna for Wireless Applications", IEEE Antennas and Wireless Propagation Letters, Vol. 13, pp. 118-121, 2014.

[18] Toshifumi Moriyama, Federico Viani, Marco Saluci, Fabrizio Robol, and Enrico Giarola, "Planar multiband antenna for 3G/4G advanced wireless services", IEICE Electronics Express, Vol. 11, No. 17, 1-10, 2014.

[19] Ansoft High Frequency Structure Simulation HFSS software ver.13, 2010. 